\title{
OPTIMIZATION OF FRICTION STIR WELDING PROCESS
}

\section{PARAMETER USING TAGUCHI METHOD AND RESPONSE SURFACE METHODOLOGY: A REVIEW}

\author{
Satish P. Pawar ${ }^{1}$, M. T. Shete ${ }^{2}$ \\ ${ }^{1}$ M.Tech. student, Production Engineering, Govt. College of Engineering, Amravati, (M.S.) India. \\ ${ }^{2}$ Asst. Professor, Mechanical Engineering Department, Govt. College of Engineering, Amravati, (M.S.)India \\ satishpawar854@gmail.com,mtshete@yahoo.com
}

\begin{abstract}
Friction stir welding (FSW) is relatively new solid state joining process. This joining technique is energy efficient, environment friendly and versatile. Welding is a multiinput-output process in which quality of welded joint is depends upon a input parameter. Therefore optimization of input process parameter is required to achieve good quality of welding. There are so many methods of optimization in which Taguchi method and Response surface methodology are selected for optimization of process parameter. In this review the effect of process parameter on welded joint studied and optimizes the parameter by using Taguchi method and Response surface methodology. The study of Friction stir welding of Aluminium alloy and High density polyethylene sheets shows the improvement in welded joint quality by optimization of process parameter. The main process parameters which affect the strength of welded joint is tool rotational speed, welding speed, axial force and tool pin profile.
\end{abstract}

Keywords: Friction stir welding (FSW), Optimization, Taguchi Method Response surface Methodology Prediction models $* * *$

\section{INTRODUCTION}

Friction stir welding (FSW) is a solid state welding process invented and patented by The Welding Institute (UK) in1991[1]. It is one of the most significant developments in the area of welding. FSW offers the potential for joints with high fatigue strength; low preparation and little post weld dressing and ability to join dissimilar material.[2] It involves joint formation below the base material melting temperature. Compared to many of the fusion welding processes that are routinely used for joining structural alloys, friction stir welding is an emerging solid state joining process in which the material that is being welded does not melt and recast. Avoiding melting prevents many of the metallurgical problems that occur with conventional fusion welding, such as distortion, shrinkage, porosity and splatter.[4].

\subsection{Process}

A non-consumable rotating tool with designed pin and shoulder is inserted into the edges of the plates to join. The pin traverses along the line of joint and the shoulder touches the plates. Due to friction, the tool heats the work piece and moves the material from a side to the other. Material plastic deformation also increases the overall heat generated during the pin and the combination of the pin rotation and translation results in producing a welded joint in solid state.[3] Good quality of welded joint between dissimilar materials is a very useful for many emerging application including the ship building, aerospace, transportation, power generation, chemical nuclear industries.[2]

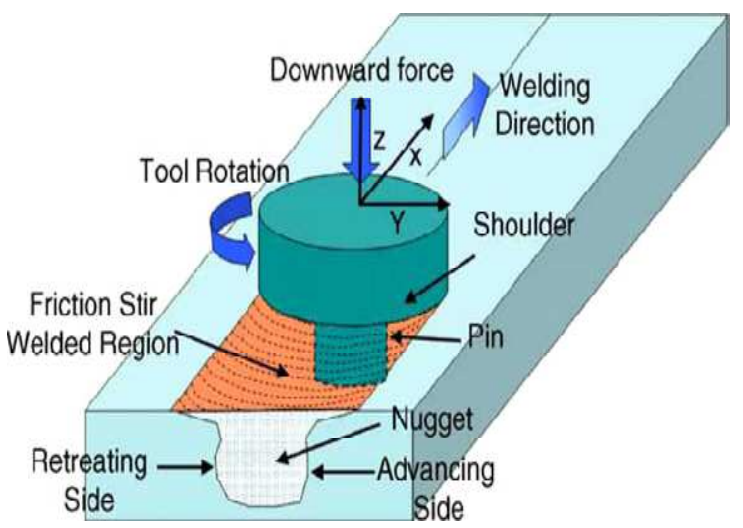

Fig-1. Illustration of Friction Stir Welding.

\subsection{Optimization of Welding Parameter}

The quality of a weld joint is directly influenced by the welding input parameters during the welding process; therefore input parameters plays a major role in deciding quality of welded joint[8]. Various industries of welding follow the conventional experimental procedure i.e. varying one parameter at a time while keeping the other parameter 
constant. This conventional parametric design of the experimental approach is time consuming and requires excessive resources[12]. To solve this problem there are different methods of achieving the desired output variables by developing new models. In this review two methods of optimization are studied i.e. Taguchi Method and Response surface methodology[9]

Taguchi technique has been used widely for product or process on determining parameters and their performance measure with minimum variation. It is an efficient problem solving tool which can improve the performance of the product, process, design and system with a significant slash in experimental time and cost[13].

Response Surface Methodology (RSM) is a collection of mathematical and statistical techniques useful for the modeling and analysis of problems in which a response of interest is influenced by several variables and the objective is to optimize this response[20]. The RSM is important in designing, formulating, developing, and analyzing new scientific studies and products. It is also efficient in the improvement of existing studies and products. RSM will be used to reduce the number of experiments, in addition to build a numerical relation between the quality of welding and the welding parameters.[23]

\section{OPTIMIZATION MODELS OF FSW BY}

\section{TAGUCHI}

The optimization models for FSW are develop by considering a set of parameters in most cases tool rotational speed, welding speed and axial force. The use of numerical techniques that are specifically develop to reduce the cost of expensive computer simulation are also available. These include Space and Manifold technique, Genetic Algorithm (GA), Stepecent Descent optimization and taguchi method. Mohamadreza Nourani et al reviewed this technique.[29]In this review study Taguchi optimization technique is focused for review on optimization model. M Jayaram et al[11] they optimize the FSW of cast aluminium alloy process parameter such as Tool rotation speed, Welding speed and axial force and evaluate. Optimum welding condition for maximizing tensile strength is determined. In this study they found that the Tool rotation speed is most Dominant parameter for tensile strength followed by welding speed. Axial force shows minimal effect on tensile strength compared to other parameter. A maximum tensile strength (147 Mpa) exhibited with optimal process parameters tool rotation speed $1200 \mathrm{rpm}$, welding speed $40 \mathrm{~mm} / \mathrm{min}$ and axial force $4 \mathrm{KN}$. The same parameters studied by A.K.Laxminarayan et al[12] in friction stir welding of RDE-40 Aluminium alloy of $6 \mathrm{~mm}$ thickness plate by butt joint . They also found that Tool rotational speed has more contribution as compared to other parameters i.e.41 $\%$ and traverse speed $-33 \%$, axial force- $21 \%$ and the value of this optimum parameters for RDE $40 \mathrm{Al}$ alloy is 400rpm,
$45 \mathrm{~mm} / \mathrm{min}$ and $6 \mathrm{KN}$ respectively.P. Murali et al [15] join the 5mm thickness dissimilar AA2024-T6 and AA6351-T6 Al alloy by FSW and study the same parameters. Their results obtain are $1200 \mathrm{rpm}(67.31 \%), 1.2 \mathrm{~mm} / \mathrm{s}(13.7 \%)$ and $7000 \mathrm{~N}$ $(14.5 \%)$ respectively.

The following researcher study some different parameters in same type of welding with different material M Koilraj et al[10] join the dissimilar Al-Cu alloy AA2219-T87 and AA5083-H321 of $6 \mathrm{~mm}$ thickness. The parameters taken are Tool rotation speed, Transeverse speed and D/d ratio. Cyllindrical threded pin profile found best among other tool profile and contribute $60 \%$ to the overall contribution the results obtain are $1200 \mathrm{rpm}, 15 \mathrm{~mm} / \mathrm{min}$ and $\mathrm{D} / \mathrm{d}$ is 3 respectively. C Vidal et al [19] optimize the the friction stir welding parameter to improve the Tensile strength and bending toughness of AA2024-T351 alloy. The parameters considered was vertical downward force, traverse speed and pin length. They improve the Tensile strength and bending toughness by $2.8 \%$ and $10 \%$ by optimization.

High Density Polyethlene is one of the important material in the class of thermoplastic material. It is replaced by conventional material to reduce the weight of component. Therefore joining of HDPE by FSW is also increasing demand some researcher study the optimization of process parameters in FSW of HDPE.

Mohammad Ali Rezgui et al [6] optimize the friction stir welding process parameter of High Density Polyethylene 15 $\mathrm{mm}$ sheets by linear welding. They investigate the effects of rotation speed, feed speed and tool plunge surface on longitudinal flow stress. They optimize the parameter Tool rotation speed, feed speed and tool plunged surface. Yahya Bozkurt [18] joined $4 \mathrm{~mm}$ HDPE sheets and study the parameters Tool rotation speed, Tool traverse speed and Tilt angle and results obtained are $3000 \mathrm{rpm}, 115 \mathrm{~mm} / \mathrm{min}$ and $3^{\circ}$ respectively.

In This section optimization of Friction Stir Spot welding is carried to optimize the parameters for Lap joint welding. Mustafa K Bilici et al [9] optimize the parameters of $4 \mathrm{~mm}$ thick polypropylene. They study effect of process parameters Tool rotational speed, Plunge depth and dwell time on weld strength and optimize to obtain maximum strength. The optimize parameters are tool rotational speed $900 \mathrm{rpm}$, plunge depth $5.7 \mathrm{~mm}$ and dwell time $100 \mathrm{sec}$. Mohammad Hasan hojaeefard et al [13] investigate the effect of tool rotational speed, tool tilt angle and traverse speed in FSW of Aluminium to Brass $2.5 \mathrm{~mm}$ sheets. The results obtained are $1120 \mathrm{rpm} 1.5$ $\circ$ and $6.5 \mathrm{~mm} / \mathrm{min}$ respectively they found that rotational speed plays vital role and contributes $40 \%$ in overall contribution. Yahya Bozkurt et al [16]join the $1.6 \mathrm{~mm}$ AA2024-T3 and $1.5 \mathrm{~mm}$ AA5754-H22 aluminium alloys. Two cases are studied in first case one plate took over another and in second case vice versa. They conclude that the 
improvement in the LSFL from the initial welding parameter to the optimal welding parameter was obtained for case 1 about $47 \%$ from 3.55 to $5.28 \mathrm{KN}$ and only $1.1 \%$ for case 2 from 5.29 to $5.64 \mathrm{KN}$. In this Leonardo C.C. et al [17] replace the parameter Tilt angle by dwell time and optimize them in FSW of AZ31 Mg alloy $2 \mathrm{~mm}$ thickness Tool plunge depth has the greatest influence on shear strength of joint and around $60 \%$ contribution. The optimize parameters are rotational speed $2500 \mathrm{rpm}$, tool plunge depth $3 \mathrm{~mm}$ and dwell time 1.5 sec.

\section{PREDICTION MODELS OF FSW BY RESPONSE SURFACE METHODOLOGY}

The Mathematical models developed to predict the output response and establish the relationship between input parameter and output response by optimization. The various methodology i.e. Response Surface Methodology and Artificial Neural Network for developing mathematical models are used in which Response Surface Methodology is reviewed in this study. It has been proved by several researchers that efficient use of statistical design of experimental techniques allows development of an empirical methodology to incorporate a scientific approach in the fusion welding procedure.[25] V. Balasubramanian et al [20] developed the empirical relationship to predict the tensile strength of friction stir welded AA2219 Aluminium alloy of $6 \mathrm{~mm}$ thickness joints by incorporating welding parameters and tool profiles. Mathematical model predict that the joint fabricated using square pin profile tool with rotational speed $1600 \mathrm{rpm}$, welding speed $0.75 \mathrm{~mm} / \mathrm{sec}$ and axial force $12 \mathrm{KN}$ exhibited superior tensile properties. R.Palanivel et al [21] joined $6 \mathrm{~mm}$ thickness AA6315 aluminium aaloy by butt joint. They conclude that increase in tool rotational speed, welding speed and axial force increase the ultimate tensile strength and yield strength it reaches maximum and then decreases.But in AA6061-T6 and AA7075-T6 al alloy ultimate tensile strength increases with only increase in tool rotational speed and welding speed upto and decreases with increases in axial force.G.Elathrasan[22]. A.K.Laxminarayan et al [25] and V Balasubramanian et al [26] develop mathematical model on same parameters in FSW of AA7039 Al alloy $6 \mathrm{~mm}$ thickness and RDE $40 \mathrm{Al}$ alloy. Rotational speed has greater influence on tensile strength. maximum tensile strength of $319 \mathrm{Mpa}$ is exhibited with optimized parameter of $1460 \mathrm{rpm}$ rotational speed, $40 \mathrm{~mm} / \mathrm{min}$ welding speed and $6.5 \mathrm{KN}$ axial force. With above parameters R.Palanivel et al [24] study the Tool pin profile in FSW of AL alloy dissimilar AA6351-T6 and AA5083-T6 $6 \mathrm{~mm}$ butt joint. the joints fabricated straight square pin profiled tool with a rotational speed of $950 \mathrm{rpm}$, welding speed of $63 \mathrm{~mm} / \mathrm{min}$ and axial force of $14.72 \mathrm{kN}$ exhibited superior tensile quality. Jawdat A. Al-Jarah et al [23] vary the thickness of the welding plate of aluminium alloy from 4 to 8 thickness and develop empirical relationship to predict the yield strength and hardness of joint. Tool rotational speed, welding speed and tool shoulder diameter are also taken into consideration. I Dinaharan et al [27] identify a set of friction stir welding parameters to join aluminium matrix composites which will give higher tensile strength, ductility and wear resistance. The process parameters considered were tool rotational speed, welding speed, axial force and weight percentage of $\mathrm{ZrB} 2$. Mathematical models were developed and optimize using generalized reduced gradient method. The results obtained are tool rotational speed $1132 \mathrm{rpm}$, welding speed $51 \mathrm{~mm} / \mathrm{min}$, axial force $5.8 \mathrm{kN}$ and $\mathrm{ZrB} 2$ is $10 \mathrm{wt} . \%$. The predicted parameters are UTS 226 $\mathrm{Mpa}, \mathrm{E} 0.76 \%$ and $\mathrm{W} 286.15^{*} 10^{-5} \mathrm{~mm}^{3} / \mathrm{m}$. The optimize process parameters can be used to automate the FSW process to achieve desirable joint properties.

\section{CONCLUSIONS}

- From the above review it is conclude that Tool rotational speed, Welding speed, Axial force and Tool pin profile are most significant parameters. Optimizing these parameters gives better quality of welded joint.

- In this review two methods for optimization are studied i.e. Taguchi method and Response surface methodology

- Taguchi method gives the optimize parameters for getting desire output while Response surface methodology establish empirical relationship between welding input input parameter and output response and develop the mathematical model to predict the output response.

- In this review study mostly the $6 \mathrm{~mm}$ thickness sheets are taken for and most of the researchers prefer the butt joint for linear welding.

- The predicted results by optimization is very closure to actual experimental value

\section{REFERENCES}

[1]. W. M. Thomas, E. D. Nicholas, J. C. Needham, M. G.Murch, P. Temple-Smith and C. J. Dawes, "Friction Welding," The Welding Institute TWI (1991) Patent Application No. 91259788, Cambridge, 1991.

[2]. Friction Strir Welding Technical Handbook, www.esab.com

[3]. H. Lombard, D.G. Hattingh, A. Steuwer, M.N. James, "Optimising FSW process parameters to minimise defects and maximise fatigue life in 5083-H321 aluminium alloy", Engineering Fracture Mechanics, Vol.75, 2008,pp.341-354

[4]. Mustafa K. Bilici, "Effect of tool geometry on friction stir spot welding of

Polypropylene sheets", eXPRESS Polymer Letters Vol.6, No.10, 2012, pp. 805-813

[5]. Erica Anna Squeo, Giuseppe Bruno, Alessandro Guglielmotti, Fabrizio Quadrini "Friction Stir Welding Of Polyethylene Sheets" ISSN, 2009, pp. 1221-4566

[6]. Mohamed-Ali Rezgui, Ali-Chedli Trabelsi, Mahfoudh Ay adi, Khaled Hamrounic "Optimization of Friction Stir Welding Process of High Density Polyethylene", International 
Journal of Production and Quality Engineering, Vol. 2, No. 1, January- June 2011, pp. 55-61

[7]. Amir Mostafapour,Ehsan Azarsa, "A study on the role of processing parameters in joining polyethylene sheets via heat assisted friction stir welding: Investigating microstructure, tensile and flexural properties", International Journal of the Physical Sciences, Vol. 7(4), 23 January 2012, pp. 647 - 654 [8]. Mustafa Kemal Bilici, Ahmet Irfan Yükler, "Influence of tool geometry and process parameters on macrostructure and static strength in friction stir spot welded polyethylene sheets", Materials and Design, Vol.33, 2012, pp.145-152

[9]. Mustafa Kemal Bilici, "Application of Taguchi approach to optimize friction stir spot welding parameters of polypropylene", Materials and Design, Vol.35, 2012, pp.113119.

[10]. M. Koilraj, V. Sundareswaran, S. Vijayan, S.R. Koteswara Rao, "Friction stir welding of dissimilar aluminum alloys AA2219 to AA5083 -Optimization of process parameters using Taguchi technique", Materials and Design, Vol.42, 2012, pp.1-7.

[11]. M Jayaram, R Sivasubramanian, V Balasubramanian, A K Lakshminarayanan, "Optimization of process parameters for friction stir welding of cost aluminium alloy A319 by Taguchi method", Journal of Scientific \& Industrial Research, Vol. 68,2009,pp.36-43.

[12]. A. K. Lakshminarayanan, V. Balasubramanian, "Process parameters optimization for friction stir welding of RDE-40 aluminium alloy using Taguchi technique", Transactions of Nonferrous Metals Society of China, Vol.18, 2008, pp.548554.

[13]. Mohammad Hasan Shojaeefard, Abolfazl Khalkhali, Mostafa Akbari, Mojtaba Tahani, "Application of Taguchi optimization technique in determining aluminum to brass friction stir welding parameters", Materials and Design, Vol.52, 2013, pp.587- 592.

[14]. Mohamed-Ali Rezgui, Ali-Chedli Trabelsi, Mahfoudh Ayadi, Khaled Hamrouni, "Optimization of Friction Stir Welding Process of High Density Polyethylene", International Journal of Production and Quality Engineering, Vol.2, 2011, pp.55-61

[15]. P. Murali Krishna, N. Ramanaiah, K. Prasada Rao, "Optimization of process parameters for friction Stir welding of dissimilar Aluminum alloys (AA2024 -T6 and AA6351-T6) by using Taguchi method", International Journal of Industrial Engineering Computations, Vol.4, 2013, pp.71-80

[16]. Yahya Bozkurt, Mustafa Kemal Bilici, "Application of Taguchi approach to optimize of FSSW parameters on joint properties of dissimilar AA2024-T3 and AA5754-H22 aluminum alloys", Materials and Design, Vol.51, 2013, pp.513-521

[17]. Leonardo Contri Campanelli, Uceu Fuad Hasan Suhuddin, Jorge Fernandez dos Santos, Nelson Guedes de Alcântara, "Parameters Optimization for Friction Spot Welding of AZ31 Magnesium Alloy by Taguchi Method", Soldag. Insp. São Paulo, Vol.17, 2012, pp.26-31.
[18]. Yahya Bozkurt, "The optimization of friction stir welding process parameters to achieve maximum tensile strength in polyethylene sheets", Materials and Design, Vol. 35, 2012, pp.440-445.

[19]. C. Vidal, V. Infante, P. Peças, P. Vilaça, "Application Of Taguchi Method In The Optimization Of Friction Stir Welding Parameters Of An Aeronautic Aluminium Alloy"

[20]. K. Elangovan, V. Balasubramanian, S. Babu, "Developing an Empirical Relationship to Predict Tensile Strength of Friction Stir Welded AA2219 Aluminum Alloy", Journal of Materials Engineering and Performance, Vol. 17(6), 2008, pp.820-830.

[21]. R. Palanivel, P. Koshy Mathews, N. Murugan, "Development of mathematical model to predict the mechanical properties of friction stir welded AA6351 aluminum alloy", Journal of Engineering Science and Technology, Vol. 4(1), 2011, pp. 25-31.

[22]. G. Elatharasan, V.S. Sethil Kumar, "Modelling and Optimization of friction stir welding parameters for dissimilar aluminium alloys using RSM", Procedia Engineering, Vol. 38, 2012, pp.3477-3481.

[23]. Jawdat A. Al-Jarrah, Sallameh Swalha, Talal Abu Mansour, Masoud Ibrahim, Maen Al-Rashdan, "Optimization of Friction Stir Welding Parameters for Joining Aluminum Alloys Using RSM", Adv. Theor. Appl. Mech., Vol. 6, no. 1, 2013, pp.13-26.

[24]. R. Palanivel, P. Koshy Mathews, N. Murugan, "Development of mathematical model to predict the ultimate tensile strength of friction stir welded dissimilar aluminum alloy", ISSN, Vol. 18(5), 2012, pp. 517-523.

[25]. A. K. Lakshminarayanan, V. Balasubramanian, "Comparison of RSM with ANN in predicting tensile strength of friction stir welded AA7039 aluminium alloy joints", Transactions of Nonferrous Metals Society of China, Vol.19, 2009, pp.9-18.

[26]. Balasubramanian V, Lakshminarayanan A K, "Comparison of response surface model with neural network in predicting the tensile strength of friction stir welded RDE40 aluminium alloy", Journal on Design and Manufacturing Technologies, Vol.1, 2007

[27]. I Dinaharan, N. Murugan, "Automation of Friction Stir Welding process to join Aluminium Matrix composite by Optimization", Procedia Engineering, Vol. 38, 2012, pp.105110.

[28] K. Y.Benyounis, A. G. Olabi, "Optimization of differet welding process using statistical and numerical approaches A reference guide", Advances in Engineering software, Vol.39, 2008, pp.483-496.

[29]. Mohamadreza Nourani, Abbas S. Milani, Spiro Yannacopoulos, "Taguchi Optimization of Process Parameters in Friction Stir Welding of 6061 Aluminum Alloy: A Review and Case Study". Scientific research, Vol.3, 2011, pp.144-155 